\title{
HYBRIDIZED OPTIMIZATION APPROACHES TO THE SCHEDULING OF MULTI-PERIOD MIXED-BTU NATURAL GAS PRODUCTS
}

\author{
Michael Bond \\ Floyd H. Grant \\ Industrial and Systems Engineering \\ University of Oklahoma \\ Norman, OK 73019, USA
}

\begin{abstract}
Decisions regarding the buying, storing and selling of natural gas are difficult facing the high volatility of prices and uncertain demand. The increasing availability of low-Btu gas complicates decisions faced by investors and operational planners of consumers of natural gas. This study examines multiple approaches to maximizing profits by optimally scheduling the purchase and storage of two gas products of different energy densities and the sales of the same combined with a blended third product. Three approaches, a Branch and Bound-linear programming hybrid, a stochastic search algorithm-linear programming hybrid, and a pure random search are developed and tested in simulated environments. To make each technique computationally tractable, constraints on the units of product moved in each transaction are implemented. Using numerical data, the three approaches are tested, analyzed and compared statistically and graphically along with computer performance information. The result provides a basis for planners to improve decision making.
\end{abstract}

\section{INTRODUCTION}

Investors in natural gas seek to maximize profit by taking advantage of the seasonal low and high prices. Decisions regarding buying, storing and selling natural gas are difficult in the face of high variability of prices and uncertain demand. Various investment and management strategies exist. Operational planners for commercial and industrial consumers of natural gas use various techniques for planning the buying, storage and selling of the product.

This paper describes our approach of combining simulation and linear programming to optimize the decision process. While the focus is multi-cavern salt dome storage facilities, which have faster inventory turnover rates than the more common reservoir storage facilities, it is recognized that not all gas discussed in this paper is stored in such facilities (FERC 2004).

With economical stresses and increased emphasis on the protection of Earth's environment, the use of natural gas from alternate sources has increased. In many cases, such gas contains a lower energy content or Btu level, and while it may not be economically feasible to remove the impurities, it may still be desirable to use the gas rather than simply burning or 'flaring' it (EPA 2012). Further complicating the problem is that the price curves of gas from different sources may not be synchronized.

Consumers and investors seek a means of executing the planning process in the presence of gases of differing energy content levels. The primary purpose of this research is to acquire knowledge of techniques for optimizing the scheduling of buying, storage and selling of natural gas inventories of differing heat contents, specifically to maximize profits or minimize costs in these operations. Much work has been done in the area of scheduling standard pipeline-ready gas, but there exists a gap in the literature regarding mixed content gas. This problem has nuances that differentiate it from existing research on mixed-product problems. Further, the nature of natural gas and how it is stored distinguishes it from most 


\section{Bond and Grant}

commodities. For example, one distinctive characteristic of gas storage is that the rate of injection or delivery is related to the amount in storage at the time (Holland 2008).

The contribution this study makes in two areas lends to its significance. First, it adds to the research in this field by contribution to the study of mix-product natural gas scheduling. It provides initial information regarding the optimization of natural gas storage and scheduling, a logistical and financial problem that has been studied a long time and will continue to be investigated.

Secondly, it adds to the body of environmental studies work. Methane is the primary component of natural gas and is present in other bio-generated gases. It is considered to be a contributor to global warming and is seen as a pollutant when released into the atmosphere. As more and more low-Btu gas is captured to be used rather than released into the environment it is desirable to optimize its distribution and consumption.

Three common numerical approaches that are applied to the valuation of gas in storage: Monte Carlo simulation, numerical partial differential equation techniques and binomial/trinomial trees (Holland 2007). Stochastic optimization techniques find widespread use in simulation optimization. When modeling natural gas storage and scheduling, it is common to use a Monte Carlo process to simulate the forward price curve, (Blanco 2002; Bjerksund et al. 2011).

The practice of treating actual business opportunities as financial instruments is known as "real options theory." Frayer and Uludere (2001) identify five key components of real options: value of asset, exercise or strike price, time to expiration, volatility and risk-free rate. They modify the Black-Scholes model to real options and use it to evaluate a power production facility (Black and Scholes 1973). Lai, et al. (2011) combined real option theory and stochastic-dynamic-programming to achieve a more tractable model for valuating liquid natural gas storage. Longstaff and Schwartz (2001) developed an approach to valuing American options through simulation using a least-squares approach. The framework of this approach was based on Black and Scholes' work. Boogert and Jong (2008) adapted this approach to include complexities of natural gas storage, such as injection and withdrawal rates and working volume, and used Monte Carlo to model prices.

In the next section of this paper the problem will be defined. Section 3 describes the methodologies applies and the results are discussed in the fourth section. Finally, Section 5 presents conclusions and ideas for further investigation.

\section{PROBLEM DEFINITION}

Natural gas has a cyclical demand pattern-- low in the fall, high in the winter as temperatures drop, low again in the spring, and then slightly higher in the hotter months as the demand for electricity for cooling increases. To hedge against the cyclical demand pattern, gas is placed into underground storage. Investors and operators of gas-consuming facilities seek ways to optimize the decision to buy, sell or hold natural gas when there exist gases of different energy contents. Buyers of natural gas, whether as an investment tool or for consumption, seek to take economic advantage of the cyclical nature of gas prices, balancing seasonal cost differentials against storage costs. In this model, consumption is thought of as an exchange of gas for heat or energy and is viewed as a sale at the market spot buy price.

The heat content or heat of combustion is the energy released when a substance undergoes combustion with oxygen under standard conditions, $60^{\circ} \mathrm{F}$ and 14.696 psia. This may be known as heat of combustion, heating value or calorific value. Units are expressed as heating value per unit mass or volume. British thermal unit (Btu) per cubic foot is a common measurement of natural gas (NIST 2010). This value is typically expressed in units or energy per unit mass, (which may be expressed as volume for gasses at standard conditions).

Natural gas, though mostly methane, contains other hydrocarbons such as ethane, propane, and butane or other impurities which may increase or, more likely, decrease the heat content. While the heat content may range from 500 to $1500 \mathrm{Btu} / \mathrm{ft}^{3}$, most gas has a heat content value in the range of 900 to $1100 \mathrm{Btu} / \mathrm{ft}^{3}$ and before being transported via the US interstate pipeline systems, gas must have a heat content of approximately $1030 \mathrm{Btu} / \mathrm{ft}^{3}$. 


\section{Bond and Grant}

Typical natural gas contracts are normally written on a 12-month basis and gas is priced for delivery to the Henry Hub in Louisiana (Holland 2007). The price of gas obtained from other points on the interstate pipeline will be offset to reflect the transportation cost from the Henry Hub (NEB 2001).

The following notations are used throughout the paper. Given period i, define

\begin{tabular}{|c|c|}
\hline $\mathrm{C}_{\mathrm{A}}$ & Cost of Gas $_{A}$ \\
\hline $\mathrm{C}_{\mathrm{Ab}}$ & Cost of $\operatorname{Gas}_{\mathrm{AB}}$ \\
\hline $\mathrm{CAP}_{\mathrm{A}}$ & Max Facility Storage Capacity of Gas \\
\hline $\mathrm{CAP}_{\mathrm{B}}$ & Max Facility Storage Capacity of Gas \\
\hline $\mathrm{C}_{\mathrm{B}}$ & Cost of Gas \\
\hline $\mathrm{CS}_{\mathrm{A}}$ & Storage cost of $\operatorname{Gas}_{\mathrm{A}} \$ /$ unit/month \\
\hline $\mathrm{CS}_{\mathrm{AB}}$ & Storage cost of $\operatorname{Gas}_{\mathrm{B}} \$ /$ unit/month \\
\hline $\mathrm{H}$ & Horizon - number of time periods \\
\hline $\mathrm{I}_{\mathrm{A}}$ & Max injection rate of $\operatorname{Gas}_{A}$ \\
\hline $\mathrm{I}_{\mathrm{B}}$ & Max injection rate of $\mathrm{Gas}_{B}$ \\
\hline $\mathrm{INV}_{\mathrm{A}}$ & Facility Current Inventory of Gas $_{A}$ \\
\hline $\mathrm{INV}_{\mathrm{B}}$ & Facility Current Inventory of Gas ${ }_{B}$ \\
\hline MDVa & Max deliverable volume Gas $_{A}$ \\
\hline $\mathrm{MDVb}$ & Max deliverable volume Gas ${ }_{B}$ \\
\hline $\mathrm{p}_{\mathrm{a}}$ & 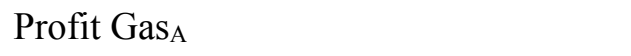 \\
\hline$p_{a b}$ & Profit Gas ${ }_{A B}$ \\
\hline $\mathrm{p}_{\mathrm{b}}$ & Profit $\mathrm{Gas}_{\mathrm{B}}$ \\
\hline $\mathrm{P}_{\mathrm{A}}$ & Sales Price of Gas ${ }_{A}$ \\
\hline $\mathrm{P}_{\mathrm{Ab}}$ & Sales Price of Gas $_{\mathrm{AB}}$ \\
\hline$P_{B}$ & Sales Price of $\mathrm{Gas}_{B}$ \\
\hline$r_{\mathrm{A}}$ & Ratio of $\operatorname{Gas}_{\mathrm{A}}$ in $\operatorname{Gas}_{\mathrm{AB}(1-} \mathrm{r}_{\mathrm{B})}$ \\
\hline$r_{B}$ & Ratio of $\operatorname{Gas}_{\mathrm{B}}$ in $\operatorname{Gas}_{\mathrm{AB}}\left(1-\mathrm{r}_{\mathrm{A}}\right)$ \\
\hline $\mathrm{R}_{\mathrm{ABi}}$ & Calculated profit of Gas $\mathrm{AB}$ in period $\mathrm{i}$ \\
\hline $\mathrm{R}_{\mathrm{Ai}}$ & Calculated profit of Gas A in period $\mathrm{i}$ \\
\hline $\mathrm{R}_{\mathrm{Bi}}$ & Calculated profit of Gas B in period $i$ \\
\hline $\mathrm{dvol}_{\mathrm{a}}$ & Change in volume of $\mathrm{Gas}_{\mathrm{A}}$ one period \\
\hline $\mathrm{dvol}_{\mathrm{ab}}$ & Change in volume of $\operatorname{Gas}_{\mathrm{AB}}$ one period \\
\hline $\mathrm{dvol}_{\mathrm{b}}$ & Change in volume of $\mathrm{Gas}_{\mathrm{B}}$ one period \\
\hline $\mathrm{V}_{\mathrm{A}}$ & Volume of Gas $_{\mathrm{A}}$ Injected \\
\hline$V_{B}$ & Volume of Gas Injected \\
\hline $\mathrm{V}_{\mathrm{A}}$ & 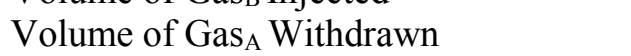 \\
\hline $\mathrm{V}_{\mathrm{AB}}$ & Volume of Gas ${ }_{A B}$ Withdrawn \\
\hline VolMax $_{A}$ & Max leased storage capacity of Gas $_{A}$ \\
\hline $\operatorname{VolMax}_{\mathrm{AB}}$ & Max leased storage capacity of $\operatorname{Gas}_{B}$ \\
\hline $\mathrm{W}_{\mathrm{A}}$ & Max withdrawal rate of $\mathrm{Gas}_{\mathrm{A}}$ \\
\hline $\mathrm{W}_{\mathrm{AB}}$ & Max withdrawal rate of $\operatorname{Gas}_{\mathrm{AB}}$ \\
\hline $\mathrm{W}_{\mathrm{B}}$ & Max withdrawal rate of $\mathrm{GaS}_{B}$ \\
\hline $\mathrm{Y}_{\mathrm{A}}$ & Number annual inventory turns for Gas \\
\hline$Y_{B}$ & Number annual inventory turns for $\mathrm{Gas}_{\mathrm{B}}$ \\
\hline
\end{tabular}

When using linear programming to find the product mix, the objective function being solved is

$$
\max \left(p_{a} d v o l_{a}+p_{a b} d v o l_{a b}+p_{b} d v o l b\right),
$$

subject to: 


\section{Bond and Grant}

$$
\begin{aligned}
& \mathrm{d} v l_{a}+\text { percentAinAB }^{*} \text { dvol }_{a b}<=M D V_{a} \\
& \mathrm{~d} \text { vol }_{b}+\text { percentBinAB }^{*} d v \mathrm{vl}_{a b}<=M D V_{b} \\
& d v o l_{a}>=0, d v^{\prime} l_{b}>=0, d v o l_{a b}>=0
\end{aligned}
$$

where $\mathrm{d}$ is change in volume and $\mathrm{p}$, the profit of that transaction.

Throughout this model, a first-in-first-out (FIFO) pricing scheme is used for calculating the cost of gas sold. $\mathrm{C}_{\mathrm{x}}$ is a function of the initial cost of inventory and cost of storage.

Multiple constraints are applied. The first is that gas must be in inventory the same month it is sold. Since gas can be sold and bought simultaneously, passing through storage, as it were, the inventory need not be in place at the beginning of the period but at the end. The second constraint is that contracted capacity, CCAP, not be exceeded.

There may be situations in which gas of one or both types is in a stream delivered directly from its source rather than in storage. In these cases, the total storage is equal to the maximum deliverable volume, effectively making the entire inventory pass through each period. Landfill gas would be such an example.

One more constraint implements a feature common to many natural gas storage contracts, i.e., that gas still in storage at the end of the contracted period is forfeited, effectively creating a product with an increasingly short shelf life. Gas injected at the beginning of a contract has an effective life of twelve months, while gas injected into storage two months prior to the end of contract has a shelf life of only two months. The penalty for having gas in storage at the expiration point of the storage contract is the loss of that gas at the current market price, the "spot" price.

The following equation encompassed these constraints and calculates value as

$$
\begin{gathered}
\text { value }=\max \sum_{i=1}^{h}\left(\left(d W_{a_{i}} p_{a_{i}} d v o l_{a_{i}}-c_{a_{i}} d v o l_{a_{i}} d I_{a_{i}}\right)+\right. \\
\left(p_{a b_{i}} d v o l_{a b_{i}} d W_{a b_{i}}\right)+ \\
\left.\left.\left(d W_{b_{i}} p_{b_{i}} d v o l_{b_{i}}-c_{b_{i}} d v o l_{b_{i}} d I_{b_{i}}\right)\right)\right)- \\
\left(\operatorname{Inv}_{a} h * \operatorname{Spot}_{a}+\operatorname{Inv}_{b} h * \operatorname{Spot}_{b}\right)
\end{gathered}
$$

where $W_{i}$ and $I_{i}$ are decision variables, taking a mutually exclusive value of 1 or 0 , representing the decision to withdraw (sell) or inject (buy) gas, respectively.

\section{METHODOLOGY}

The research examined the use of simulation optimization techniques in combination with linear programming to make optimal scheduling decisions regarding holding times, product mix values, product injection and withdrawal schedules and transactional quantities. In addition to simplified test data designed to provide clear demonstrations of functionality and accuracy, we used price and cost data from past years as input for natural gas data and estimated landfill/low-Btu gas prices based on current trends and prices (EIA 2012).

\subsection{System Configuration}

We used the simulation package Awesim and modules written in Microsoft $\mathrm{C}++$ to generate scenarios and in some cases used the linear programming package, LP_Solve 5.5 to provide the economical product mix and then evaluated the results. Using Awesim, each entity represented a potential path and contained all information required to define each period and to generate values for the next. This included all cost, price and inventory data as well as other parameters. The entity 'aged' through the time horizon, 12 months in most cases, changing value as different decisions were executed. At the end of the 12-period horizon, that value was compared to that of the best-valued decision path and replaced it if it was better. 


\section{Bond and Grant}

\subsection{Approaches}

Three approaches were developed and compared. A Branch and Bound (B\&B) algorithm combined with linear programming (LP), B\&B-LP, was developed. This hybrid was implemented as a recursively created trinary decision tree with options to buy, hold or sell gas at each node. Heuristics were applied to limit the number of nodes per branch and thereby make the algorithm more computationally tractable.

An evolutionary stochastic search algorithm (SS-LP) in combination with LP was developed. This direct stochastic search algorithm implemented the same heuristics as the B\&B-LP hybrid. Table 1 illustrates the progression from a fully direct approach to a fully stochastic one.

Finally, in order to compare the computational efficiency of the LP solver versus pure random search of the solution space, a Pure Random Search (PRS)-based approach (SS) was developed. This approach did not operate under the same bounds as the B\&B-LP and SS-LP algorithms. It used more relaxed search criteria.

Table 1: Methodologies.

\begin{tabular}{|c|c|c|}
\hline Approach & Select Decision & Select Product Mix \\
\hline $\begin{array}{c}\text { Branch \& Bound }- \\
\text { LP Hybrid }\end{array}$ & Direct & Direct \\
\hline $\begin{array}{c}\text { Stochastic Search }- \\
\text { LP Hybrid }\end{array}$ & Random & Direct \\
\hline \begin{tabular}{c} 
Stochastic Search \\
\hline
\end{tabular} & Random & Random \\
\hline
\end{tabular}

\subsection{Branch \& Bound with LP}

This type of scheduling problem, with decision points made across a finite horizon, lends itself nicely to a B\&B solution, with each node representing a decision point. Decision points in the trinary tree were created at each period of the 12-month horizon, three being generated from the previous node. While $\mathrm{B} \& \mathrm{~B}$ is conceptually simple, it is not without its limitations. Although it can produce an exact optimum, with larger problems the amount of computer time required to find that solution may be too great to be useful. Without careful pruning, the number of bud nodes on a tree increases exponentially. Mousavi et al. (2012) found this to be true, that the performance of B\&B compared to a genetic or simulated annealing algorithm, which produced near-optimal solutions, was significantly poorer.

This multi-item, product-mix, multi-period inventory problem is non-deterministic polynomial time, NP-Hard, and finding the solution is computationally infeasible. It cannot be solved efficiently as is, but it can be approached by reducing it to a simpler problem through the application of heuristics and bounds. A result of this problem restatement is that an approach that provides a near-optimal solution must suffice.

Algorithm 1: Branch and Bound Optimization with LP

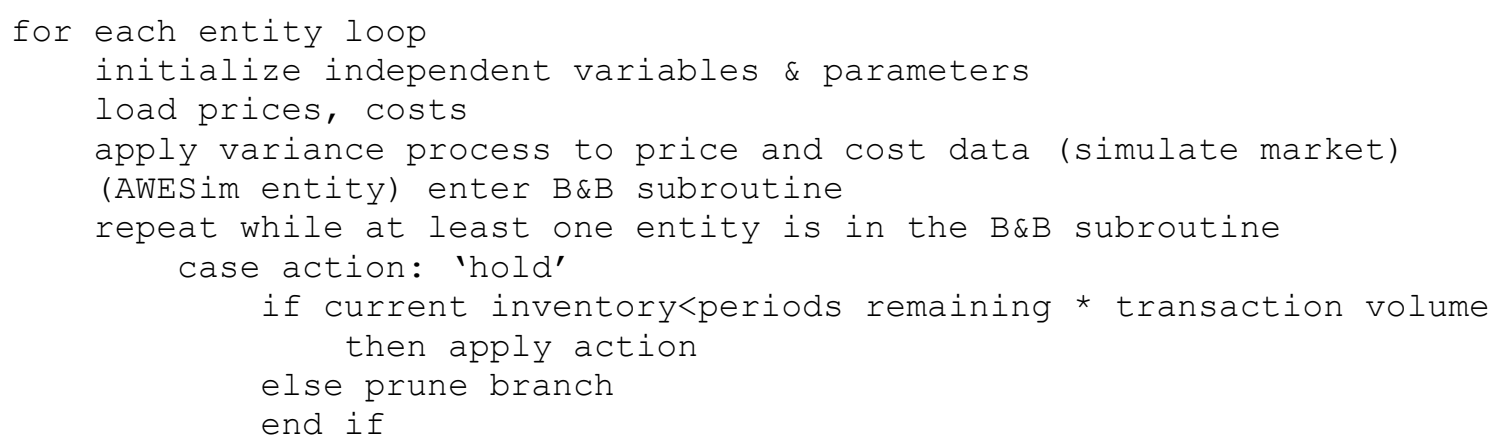




\section{Bond and Grant}

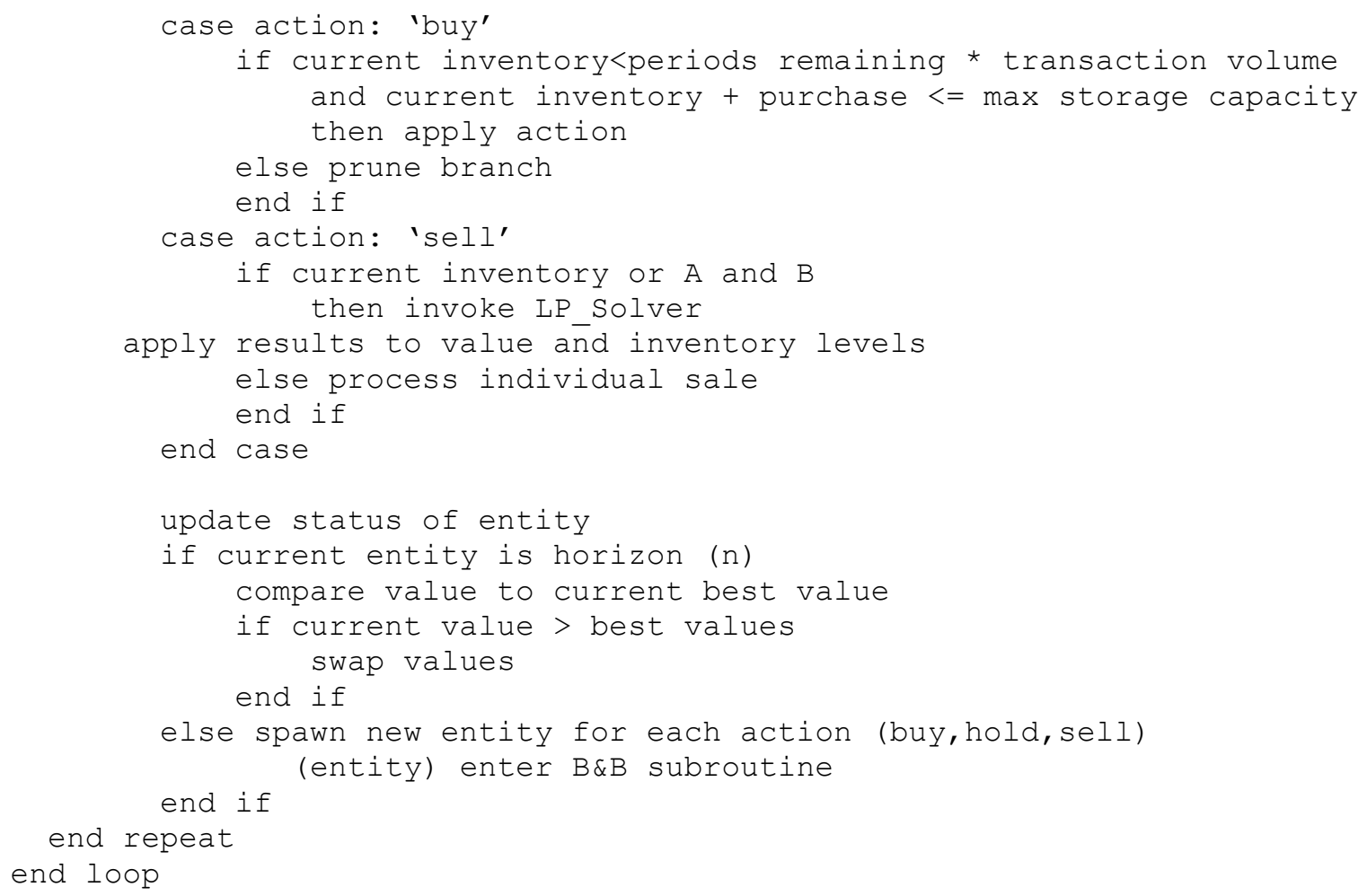

By selecting an action to be taken at a specific time, B\&B identified a subregion of the solution set. That subregion was further searched by the LP routine to find the best combination of products to sell.

\subsection{Stochastic Search with LP}

In the second approach, the use of a stochastic search (SS) routine to select sub-regions from the solution set replaced the B\&B algorithm. The decision to buy, sell or hold was then selected from a uniform random distribution with each decision receiving equal weight, i.e., there was no bias toward either of the three decision actions. Like the first approach, though, this one also used LP to optimize that selection.

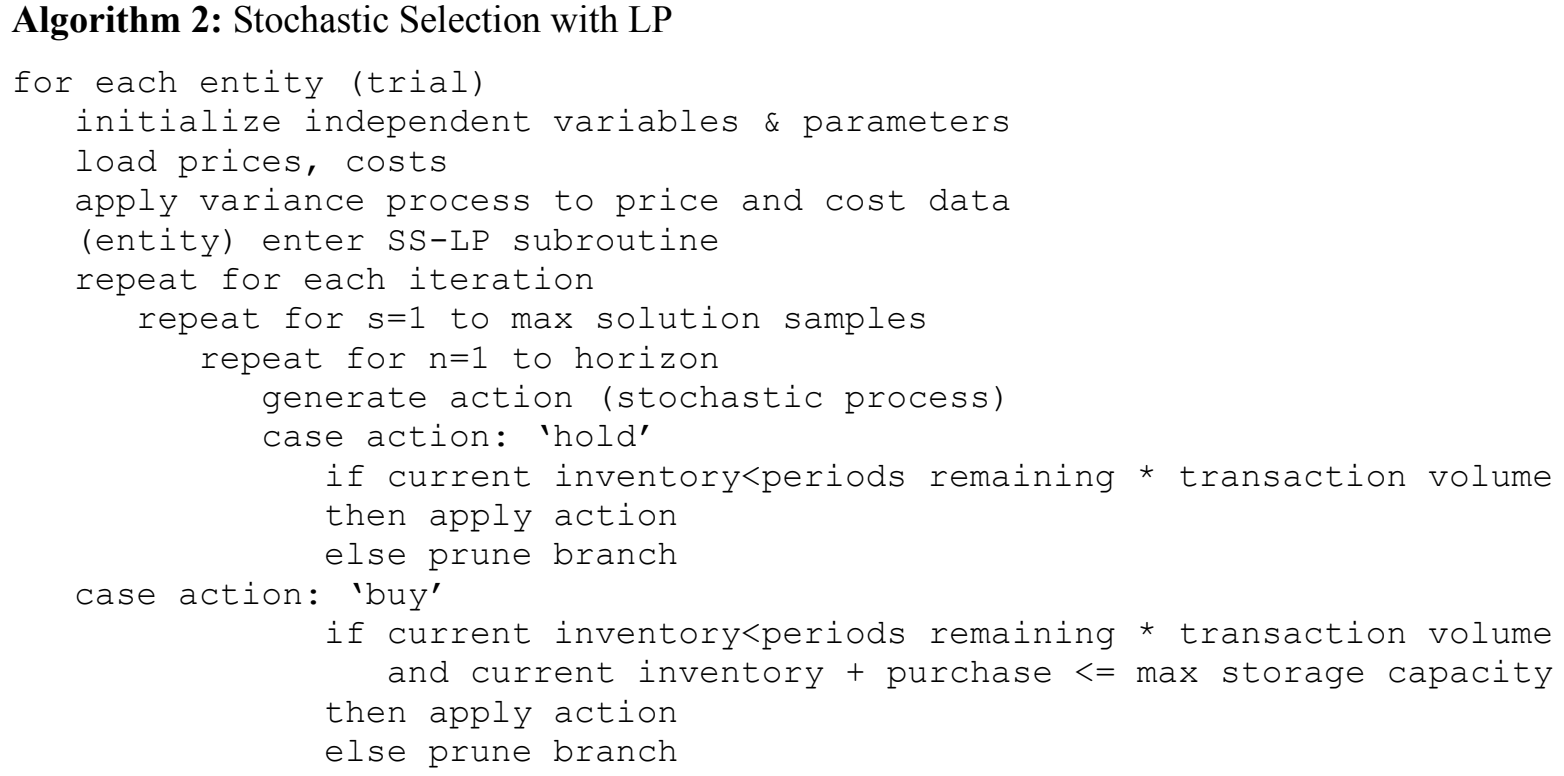




\section{Bond and Grant}

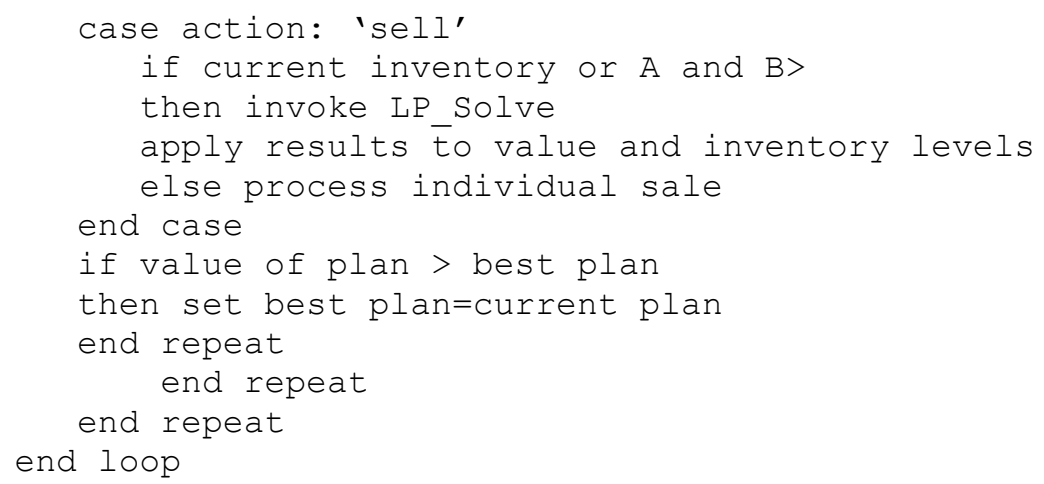

\subsection{Stochastic Search}

The stochastic search routine alone was used as the third method. Full-horizon decision paths were generated and evaluated based on random selections from the solution set, with the best result being tracked. Rather than using LP, the volume moved in each transaction was the result of a random process.

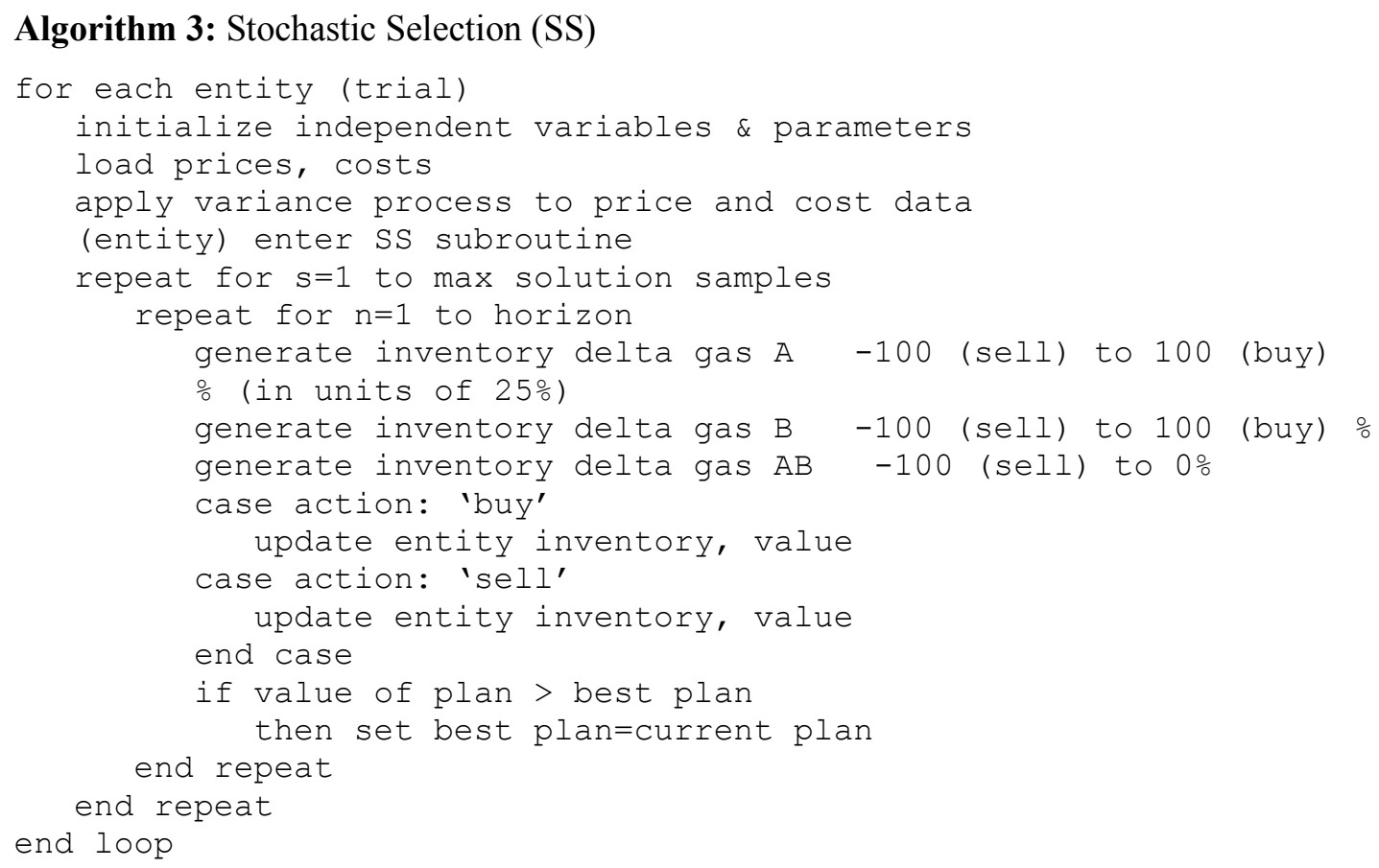

Random Search (RS) or Pure Random Search (PRS) can be used and works on an infinite parameter space when it is not possible to evaluate every possible solution. This is the general case of random solution searches, being performed without any heuristics or rules for reducing the set of solutions. The process ends after a predetermined number of searches have been completed, a limit of computer resources has been reached or an acceptable solution has been found. This process performs best when a neighborhood can be defined in the solution space (Olafsson and Kim 2002). PRS has the advantage of avoiding local maxima. While it has been applied primarily to discrete problems, its closely related technique, sample path optimization, is practiced on continuous problems (April et al. 2003). While it can be shown that RS will converge to a near-optimal solution (Shi et al. 2000), one problem with this approach is the slow speed at which convergence is reached (Tekin and Sabuncouglu 2004). 


\section{Bond and Grant}

The existence of other, more guided approaches notwithstanding, this approach does find use in practice. Poland, et al. (2011) applied a PRS algorithm to a smart home sensor placement problem and found that in $98.4 \%$ of test cases this approach produced superior results.

\section{RESULTS}

The B\&B-LP algorithm provided, not surprisingly, the most accurate results. Within the constraints placed on it, the process enumerated and evaluated each possible path in the 12-period horizon. In 25 trials, the correct solution was found each time. The number of samples evaluated was based on the maximum number of candidate paths enumerated by the trinomial tree, $3^{12}=531,441$. With the bounds placed on the algorithm, and considering the samples per second evaluated by the other approaches, it is unlikely that the solution set was fully enumerated. These results are shown graphically in Figure 1.

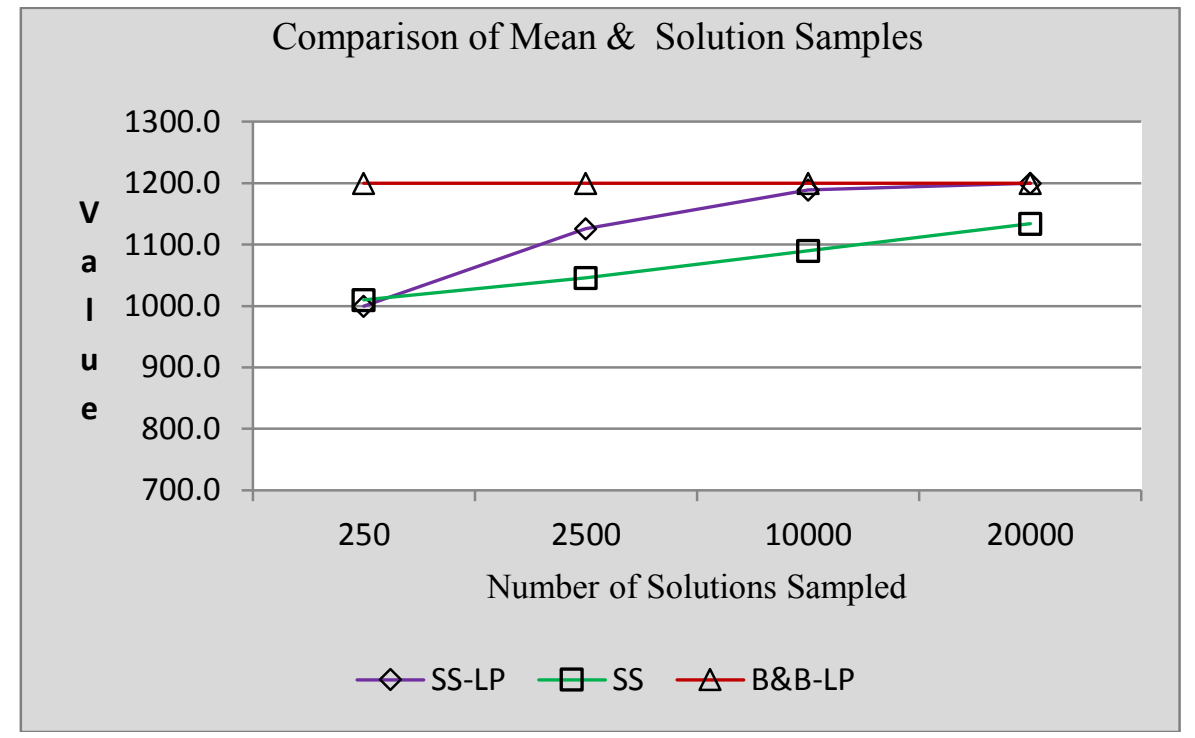

Figure 1: Best Solution Per Approach and Sample Size.

The SS-LP hybrid performed best when sampling 20000 solutions per iteration. It consistently found the optimum solutions with a STDDEV of 0.0.

The SS algorithm was created with the option of generating specific volumes of gas to be bought or sold, with a range from $-100 \%$ to $100 \%$ of the maximum transfer amount, and was initially generated in $25 \%$ increments. In practice, it turned out that this expanded the solution space to the point that the SS approach could not reliably converge to a near-optimal solution in a reasonable time. Figure 2 graphically compares the accuracy and rate of convergence with that of the baseline, B\&B-LP.

The Branch \& Bound-LP hybrid was the best of the three approaches used in this project. It returned the optimal solution and, when compared to the SS-LP and SS algorithms that actually executed long enough to generate a reliable optimum or near-optimum solution, it was the least computationally expensive.

\section{CONCLUSIONS AND FUTURE RESEARCH}

This project has sought to extend current research by examining methods of optimizing the decisions that are made by gas investors and facility operators. The specific focus was the combination of gases of different energy contents, or Btu levels. This topic grows in importance as businesses seek to optimize resources and as environment pressures dictate the consumption of gas of lesser quality. 


\section{Bond and Grant}

Simulation optimization is commonly employed to solve or find reasonable solutions to problems such as this. Gas market environment was simulated using Monte Carlo techniques and three approaches were used to optimize profit in that market.

The B\&B-LP hybrid was, within the constraints of the program, the most accurate, always returning an optimal solution and in the best time. This accuracy was generated at the expense of flexibility and perhaps oversimplification. Heuristics were applied to reduce the number of decision points at each node, exponential growth being the nemesis of dynamic programming.

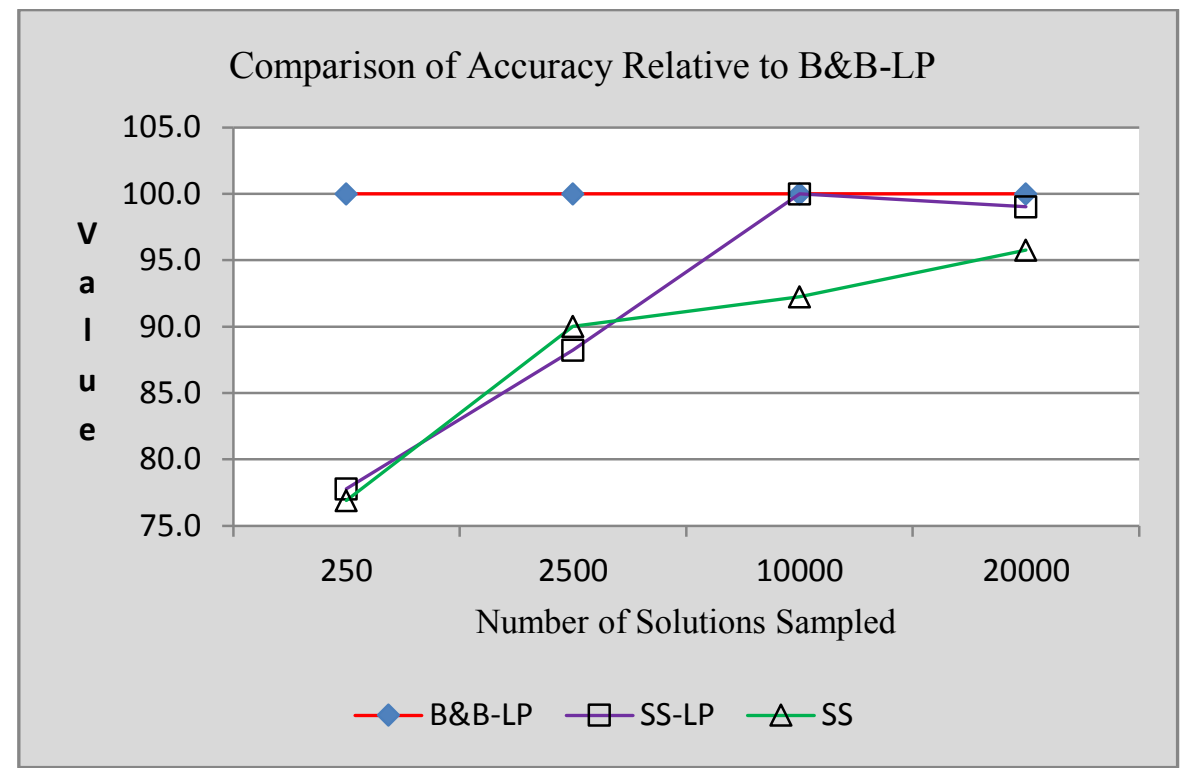

Figure 2: Accuracy of Non-Branch and Bound Approaches.

The advantage of the Stochastic Selection-Linear Programming (SS-LP) algorithms was its flexibility. It was not as efficient computationally as the B\&B-LP approach, but it was more readily modified to new constraints. While the simplest and most flexible approach, the generic Stochastic Selection (SS) algorithm proved to be too computationally expensive to use without some constraints. For example, percentage of shipping volumes were selected from a set of three options, $-100 \%, 0$, and $+100 \%$.

Quality of Solution Conclusions. Each of the three algorithms produced optimal solutions in both test cases. The B\&B-LP model found the optimal solution in the shortest time. Not surprisingly, the accuracy of the stochastic solution search routines was directly proportional to the number of sample solutions examined. The SS-LP model provided the optimal solution with a STDEV of 0.0 when 20,000 solutions were examined. The SS model exhibited the same performance.

The energy industry and natural gas in particular is a global concern and, as it faces changes from economic, technological and environmental stimuli, there will be new and important areas of research. This project has examined and offered an useable approach, an approach superior to one based solely on historical performance, to a problem that has become more prominent in the industry and will continue to receive attention.

One enhancement to the model might be to include the present value of money (PVM), in the cost function. The inclusion of futures prices and the introduction of a geometric Brownian motion function to the price variable module may also prove profitable.

\section{REFERENCES}

April, J., F. Glover, J. Kelly, M. Laguna. 2003. "Practical Introduction to Simulation Optimization." In Proceedings of the 2003 Winter Simulation Conference, Edited by S. Chick, P. J. Sánchez, D. Ferrin, 


\section{Bond and Grant}

and D. J. Morrice, 71-78. New Orleans, Louisiana: Institute of Electrical and Electronics Engineers, Inc.

Bjerksund, P., G. Stensland, F. Vagstad. 2011. "Gas Storage Valuation: Price Modeling vs Optimization Methods." The Energy Journal 32:203-226.

Black, F., M. Scholes. 1973. "The Pricing of Options and Corporate Liabilities." Journal of Political Economy 81:637-659.

Blanco, C., P. Stefiszyn. 2002. Multi-factor Models for Forward Curves Analysis: An Introduction to Principal Component Analysis. Financial Engineering Associates. Accessed February 21, 2013. http://www.docstoc.com/ docs /93749334/Multi-Factor-Models-for-Forward-Curve-Analysis.

Boogert, A., C. De Jong. 2008. "Gas Storage Valuation Using a Monte-Carlo Method." The Journal of Derivatives 15:3.81-98.

EIA 2012. "Natural Gas Prices." Energy Information Administration, Office of Oil and Gas, Accessed February 18, 2012. http://www.eia.gov.

EPA 2012. "Landfill Methane Outreach Program". Environmental Protection Agency. Accessed January 13, 2013. http://www.epa.gov/lmop/.

FERC 2004. "Current State of and Issues Concerning Underground Natural gas Storage." Federal Energy Regulatory Commission Staff Report Sept 30. Accessed January 13, 2013. www.ferc.gov.

Frayer, J., N. Uludere. 2001. "What is it Worth? Application of Real Options Theory to the Valuation of Generation Assets." The Electricity Journal. 14:8.40-51.

Holland, A. 2007. "Injection/Withdrawal Scheduling for Natural Gas Storage Facilities." In Proceedings of the ACM Symposium on Applied Computing, Edited by Y. Cho, R. L. Wainwright, H. Haddad, S. Y. Shin, Y. W. Koo, 332-333. Seoul, Korea: Association for Computing Machinery.

Holland, A. 2008. "Welfare Losses in Commodity Storage Games." In Proceedings of the $8^{\text {th }}$ International Conference on Autonomous Agents and Multi-Agent Systems Edited by K. S. Decker, J. S. Sichman,1253-1254. Budapest, Hungary.

Lai, G., M. Wang, N. Secomandi, S. Kekre, A. Scheller-Wolf. 2011. "Valuation of Storage at a Liquefied Natural Gas Terminal." Operations Research 59:3.602-616.

Longstaff, F., E. Schwartz. 2001. "Valuing American Options by Simulation: A simple Least-Squares Approach". The Review of Financial Studies 14:1.113-147.

Mousavi, S., V. Hajipour, S. Niaki, N. Alikar. 2013. "Optimizing Multi-Item Multi-Period Inventory Control System with Discounted Cash Flow and Inflation: Two Calibrated Meta-Heuristic Algorithms." Applied Mathematical Modeling 37:4.2241-2256.

NIST 2010. NIST Chemistry WebBook. Accessed April 20, 2010 http://webbook.nist.gov/ chemistry.

Olafsson, S., J. Kim. 2002. "Simulation Optimization". In Proceedings of the 2002 Winter Simulation Conference, Edited by E. Yucesan, C. H. Chen, J. L. Snowdon, J. M. Charnes, 79-84. San Diego, CA: Institute of Electrical and Electronics Engineers, Inc.

Shi, L., S. Olafsson. 2000. "Nested Partitions Method for Global Optimization." Operations Research, 48:3.390-407.

Tekin, E., I. Sabuncuoglu. 2004. "Simulation Optimization: A Comprehensive Review on Theory and Applications." IIE Transactions 36:1067-1081.

Poland, M., C. Nugent, H. Wang, L. Chen. 2011. "Pure Random Search for Ambient Sensor Distribution Optimization In A Smart Home Environment." Technology and Health Care 19:137-160.

\section{AUTHOR BIOGRAPHIES}

MICHAEL BOND received his PhD from the School of Industrial Engineering at the University of Oklahoma. He is an adjunct instructor in Computer Science at Park University, Parkville, MO. He works for Science Applications International Corporation, Inc where he applies information technology solu- 


\section{Bond and Grant}

tions to logistics and supply chain problems. He is a member of ACM. His email address is michael.bond.ok@gmail.com.

HANK GRANT is a tenured professor on the faculty of Industrial Engineering. He was formerly Director of the School of Industrial Engineering at the University of Oklahoma and is now the Director of the Center for Study of Wireless EMC. He is a member of Tau Beta Pi, IIE, and INFORMS. He serves as reviewer for a number of publications including IIE Transactions, and is a reviewer for the NSF. Dr. Grant also supports the NSF in the Office of Polar Programs. He recently served as an advisor to the United States Review Panel on Antarctica and performed an extensive analysis leading to the support for the development of a new science station at the South Pole. Dr. Grant has obtained funding from NSF, DoD, DoE and others for a variety of projects in systems modeling and simulation. Dr. Grant holds the Dugan Professorship and was the S. R. Noble Foundation Presidential Professorship at the University of Oklahoma. He teaches courses in simulation and modeling at the graduate and undergraduate levels. His email address is hgrant@ou.edu. 